\title{
3.3
}

\section{Judicialização da saúde em Minas Gerais: novas estratégias de enfrentamento: a criação do Núcleo de Atendimento à Judicialização da Saúde}

Adjudication of health in Minas Gerais: new coping strategies: the creation of the Nucleus for Assistance to Adjudication of Health

\begin{abstract}
Aline Fernanda da Silva Araújo
Advogada, especialista em Direito Público, Coordenadora Técnico-Jurídica do Núcleo de Atendimento a Judicialização da Saúde da Secretaria de Estado da Saúde de Minas Gerais. Belo Horizonte, Brasil.
\end{abstract}

Resumo: São apresentados e avaliados os resultados iniciais da nova estratégia implementada pela Secretaria da Saúde do Estado de Minas Gerais, Brasil, (SES MG) no enfrentamento da judicialização da saúde com a criação do Núcleo de Atendimento a Judicialização da Saúde, de modo a partilhar as experiências vividas, colaborando com outras localidades que porventura estejam passando por situação semelhante. A metodologia utilizada foi o PDCA - Act-Plan-Control-Do, ferramenta de gestão utilizada para definir necessidades e criar planos de ação e processos de trabalho, além de permitir o acompanhamento de resultados e correções necessárias, tudo visando a melhoria contínua dos processos de produção do cuidado em saúde. Trata-se de pesquisa-ação com participação governamental intersetorial, envolvendo a SES MG e a Advocacia Geral do Estado (AGE), onde os trabalhadores foram também pesquisadores. O resultado obtido foi a criação do Núcleo de Atendimento a Judicialização da Saúde, permitindo a responsabilização única e inequívoca pelo cumprimento das ordens judiciais dentro da SES, melhor fluxo de informações entre a SES e a AGE, diminuição do número de penalidades aplicadas ao erário público e aos gestores, além de propiciar o levantamento de dados úteis ao mapeamento e definição do perfil das demandas e seus autores. Conclui-se, nesta fase inicial pós criação do Núcleo, que sua existência será de grande valia para aprimorar as atividades de cumprimento de ordens judiciais, honrando princípios básicos da Administração Pública como eficiência e transparência, obtendo-se, como consequência direta, mais transparência e eficiência e menores danos econômicos ao erário.

Palavras chave: Judicialização de políticas de saúde; Minas Gerais, Brasil.

\begin{abstract}
The initial results of the new strategy implemented by the Secretariat of Health of the State of Minas Gerais, Brazil, (SES MG) to coping with the adjudication of health with the creation of a Nucleus for Assistance to Adjudication of Health are presented and evaluated. The methodology used was the Act-Plan-Control-Do (PDCA), a management tool aimed to define needs and create action plans and work processes, as well as monitoring the results and necessary corrections, all aimed to continuous improvement of the healthcare processes. It is a research, involving SES $M G$ and the Attorney General of the State (AGE), where workers were also researchers. The result was the creation of the Nucleus for Assistance to Adjudication of Health, allowing unique and unambiguous accountability for the compliance with court orders within the SES, better flow of information between SES and AGE,
\end{abstract}


decreasing number of penalties applied to the treasury and managers, as well as providing a useful mapping and profiling of data demands and their authors. In conclusion, the creation of the Nucleus was valuable for improving the activities of compliance with court orders, honoring basic principles of public administration as efficiency and transparency, reaching up, as a direct consequence, more transparency and efficiency and lower economic damage to the treasury.

Key words: Adjudication of health policies; Minas Gerais, Brazil.

\section{Introdução}

Diante do constante e expressivo número de demandas judiciais pleiteando o fornecimento de medicamentos, procedimentos médicos, materiais, insumos, dietas, entre outros, recebidos pela Secretaria do Estado da Saúde de Minas Gerais, constatou-se a necessidade de repensar o atendimento a esta realidade de modo a propiciar o devido cumprimento das determinações judiciais de forma mais célere e com menores danos ao erário público.

O número e as formas de penalidades aplicadas ao Estado e aos seus gestores seguem uma linha ascendente, causando grande preocupação para as Secretarias de Fazenda Estaduais e, de modo pessoal, às autoridades sanitárias, gestores do sistema de saúde, que se veem em uma encruzilhada entre a obrigatoriedade de dar cumprimento às ordens, sob penalidades diversas, e as dificuldades que enfrentam para cumpri-las.

Assim, em junho de 2013, o Secretário de Estado da Saúde, Dr. Antônio Jorge de Souza Marques, determinou dar maior atenção e reorganizar a área que cuida do cumprimento dessas ordens judicias e o fornecimento de subsídios técnicos à Advocacia Geral do Estado (AGE).

Constatada essa necessidade, houve uma reunião com o Gabinete da Governadoria com a presença da SES MG e da AGE, onde foi proposta a criação de uma nova Assessoria de Atendimento a Judicialização da Saúde.

\section{Método}

O método utilizado foi o Act-Plan-Control-Do (PDCA), com a definição de indicadores, criação de planos de ação, execução de acordo com processos, acompanhamento de resultados e ações corretivas, com enfoque no controle e melhoria contínua de processos de produção do cuidado em saúde de pacientes que judicializaram suas necessidades. 
A participação governamental intersetorial, envolvendo a SES MG e a AGE, caracterizou uma pesquisa-ação que observou os problemas junto aos grupos envolvidos, enumerou-os e implementou as propostas de intervenção ao caso concreto de modo a alterar a realidade vivida. Trabalhadores e gestores do serviço tornaram-se também pesquisadores, vez que o próprio grupo levantou suas deficiências e dificuldades, propôs alterações e as está implementando, tudo com o apoio profissional e qualificado da Assessoria de Gestão Estratégica da SES MG (AGEI).

Reuniões semanais foram realizadas a fim de identificar macroprocessos, processos, subprocessos e atividades, de forma que cada servidor envolvido nas atividades de cumprimento de ordens judiciais e prestação de subsídio técnico à Procuradoria Geral do Estado e ao Poder Judiciário foi observado, entrevistado e teve suas tarefas catalogadas, bem como seu tempo de execução medido. Modificaramse, então, os processos e fluxos de trabalho com o objetivo de melhorar o resultado do trabalho da SES MG no atendimento às demandas judiciais.

\section{Resultados}

Nesse cenário, foi criado o Núcleo de Atendimento à Judicialização da Saúde por meio da Lei Estadual № 21.077, de 27 de dezembro de 2013 (art.30).

A criação desse Núcleo teve por principal fator motivador a necessidade de se alcançar uma atuação mais eficaz e célere, diminuindo a burocracia interna e, consequentemente, diminuindo o número de penalidades aplicadas ao Estado e aos gestores da SES, tais como multas (inclusive pessoais), sequestro e bloqueio de verbas, caracterização de crime de desobediência e improbidade administrativa e, até mesmo, prisão, além do agravamento do estado de saúde e mortes de pacientes.

Além disso, a criação do Núcleo objetivou possibilitar a responsabilização única e inequívoca pelo cumprimento das ordens judiciais dentro da SES, além de uma maior aproximação entre a SES e a AGE, facilitando o fluxo de informações, tanto técnicas quanto processuais - um grande gargalo para o nosso trabalho.

O que antes era feito de forma pulverizada dentro da SES MG, com o processo de cumprimento de decisões judiciais tramitando por várias áreas internas Assessoria Técnica (demandante das compras), Diretoria de Compras de Medicamento, Diretoria de Compras de Procedimento, Regulação Assistencial, Diretoria de Contratos, Diretoria de Finanças, Assessoria Jurídica - passou para a 
gestão de um Assessor Chefe que se responsabiliza e pode gerir todo o processo de atendimento das ordens judiciais, especialmente por meio da compra de produtos e serviços de saúde.

Assim o novo Núcleo de atendimento a Judicialização da Saúde ficou composto por:

1- Assessora Chefe

2- Coordenação Administrativa

3- Coordenação Técnico-Jurídica

4- Coordenação de Compras de Procedimentos

5- Coordenação de Compras de Medicamentos

6- Coordenação de Regulação

7- Coordenação Jurídica

8- Coordenação de Dispensação de medicamentos e insumos

Além das coordenações acima, importante dar destaque à presença da AGE Procuradoria de Obrigações (PO) - cujo Núcleo de Direito Sanitário também passou a integrar a estrutura do Núcleo de Atendimento a Judicialização, ocorrendo a mudança de endereço de referido núcleo da PO para o prédio da SES MG.

Estima-se um enorme ganho com essa aproximação, de forma a acelerar o acesso a informações processuais necessárias à SES MG para o cumprimento das ordens judiciais, bem como acelerar 0 acesso da Procuradoria às informações técnicas necessárias à confecção das contestações e recursos, o que gera, como resultado final, o aporte de maior volume de informações técnicas ao Judiciário em tempo hábil, propiciando decisões tecnicamente orientadas e fundamentadas.

Pode-se dizer que o Núcleo, com pouco mais de um mês de criação, já vem apresentando grande desenvolvimento, com expressivo aumento da produtividade das áreas absorvidas. Isso porque, antes, todas as fases do processo de cumprimento das ordens judiciais eram alargadas pelos trâmites burocráticos internos e externos entre as diretorias envolvidas, o que foi abolido com o Núcleo. A aproximação dos envolvidos em um mesmo espaço físico também contribuiu de forma considerável para a melhoria das relações interpessoais, o que refletiu direta e expressivamente sobre o resultado final do trabalho.

A criação formal deste Núcleo - por lei e, inclusive, com aprovação e apoio da Casa Civil - objetivou dar tratamento diferenciado à situação enfrentada pela SES MG com as demandas judiciais. 
Entendemos haver sido alcançado esse objetivo, tendo em vista que o Núcleo segue um processo de trabalho específico e especial, levando em consideração a urgência das demandas, seja pelo caráter compelativo da ordem, seja pelo estado de saúde dos pacientes autores ou beneficiários das ações judiciais propostas.

Outra preocupação dos gestores da SES era a melhoria do atendimento aos autores da ação, no momento da entrega dos medicamentos/insumos. Isso porque, sendo a judicialização da saúde um fenômeno que avançou significativamente em um curto período de tempo, existia a dificuldade do serviço de entrega e atendimento ao público em se adaptar, de acordo com o necessário. Diante disso, o projeto de criação do Núcleo previu o aumento do número de atendentes e trabalhadores para uma triagem prévia da documentação apresentada pelos pacientes-autores, além de mudança e reorganização do espaço físico da farmácia.

Outro objetivo essencial do Núcleo é, com a utilização de sistema informatizado especialmente criado e confeccionado para a realidade da judicialização da saúde no Estado - o que passou a ocorrer em março de 2014 controlar de forma mais eficaz os estoques e compras, evitando-se perdas de produtos.

Além disso, um sistema informatizado de gerenciamento permite a visualização de relatórios detalhados e específicos sobre o perfil dos demandantes, produtos e serviços mais demandados e regiões de maior incidência das demandas. Dados dessa natureza permitem que o gestor se valha da judicialização para identificar vazios assistenciais e necessidades de atualização da política pública, convertendo, assim, decisões compelativas em mapeamento de demandas de saúde e melhorando o atendimento para a população em geral, mesmo aquela que não judicializa.

A ideia é a criação de um serviço de inteligência que identifique erros e problemas nos fluxos das redes de atendimento e também fraudes e associações indevidas com o intuito de se locupletar do dinheiro do Estado.

Permite, ainda, que se faça um estudo do perfil das decisões proferidas, identificando a necessidade de se levar mais informações técnicas a determinada comarca ou juízo. O que também reflete em ganho para a coletividade, visto que decisões tecnicamente fundamentadas, em contraponto àquelas proferidas levandose em conta apenas o caráter de emergência do caso concreto, mas considerando 
também a política pública existente, permite a concretização de uma justiça mais distributiva e também de equidade em saúde.

Por fim, outra estratégia prevista com a criação do Núcleo de Atendimento a Judicialização da Saúde mas ainda não implementada é a lotação de um técnico de saúde e de um técnico jurídico (ou Procurador do Estado) em cada cidade onde haja Superintendência ou Gerência Regional de Saúde, o que totaliza 28 cidades. Estes técnicos estarão autorizados a realizar acordos em cada caso, bem como estarão à disposição do Poder Judiciário para consultas e esclarecimentos técnicos.

\section{Conclusão}

Assim, após o planejamento realizado e a concretização da etapa de mudança de endereço físico, ocorrida em 30 de maio de 2014, e da alteração dos desenhos de fluxos e processos internos de trabalho, chegamos à fase de acompanhamento de resultados e implementação de ações corretivas advindas da análise das situações problemáticas levantadas com as mudanças realizadas e a consequente propositura de adaptações ao projeto inicial.

Reuniões semanais ainda são realizadas para identificar pendências e propor ajustes, mas a nova atmosfera de estímulo da equipe de trabalho e a finalização sensivelmente mais rápida e eficaz dos processos já podem ser sentidas pelo grupo e pelos atendidos.

Importante esclarecer que não se trata de investir mais recursos e esforços nas demandas já judicializadas em detrimento da política pública, mas, sim, de tratar o fenômeno da judicialização com a atenção que ele requer, já que sua ocorrência é inevitável ante ao cada vez maior esclarecimento da população sobre os seus direitos e a cada vez mais atuante presença da Defensoria Pública e do Ministério Público. Ademais, uma série de outros fatores influem nesse processo como as não raras associações entre indústria farmacêutica, profissionais da saúde e do direito, e o atraso na atualização das listas oficiais de medicamentos e procedimentos e na incorporação de tecnologias, se comparado à ágil capacidade da indústria farmacêutica em produzi-las, lançando novos produtos no mercado.

Além disso, cumpre destacar que, a cada demanda descumprida ou em atraso, a remessa de cópia dos autos para o Ministério Público tem sido solicitada pelos Juízos para apuração de crime, com a consequente intimação de funcionários e gestores para prestarem esclarecimentos e se defenderem em processos criminais, 0 
que vem causando grande desgaste à Administração Pública, além de dar a falsa impressão ao Judiciário de que o SUS se faz inerte quando obrigado judicialmente, gerando descrédito dos gestores, sempre tão conscientes e preocupados com o fenômeno da judicialização, mas envolvidos por um emaranhado de leis e procedimentos que não se compatibilizam com a realidade das ordens judiciais em ações de saúde.

Outra grande preocupação é o risco a que estão expostos os pacientes, sendo possível até mesmo a ocorrência de mortes devido a inércia ou inconclusão em tempo hábil dos processos por parte da SES MG. Isso já é suficientemente grave pelo fato de se ofender o direito à vida e à saúde, mas ainda traz, como consequências, ações indenizatórias e penalidades ao erário público, fazendo com que não só aqueles que não tiveram seu pleito judicial atendido a tempo saiam prejudicados, mas todo o restante da população.

Por todo exposto, podemos concluir, nesta fase inicial da criação do Núcleo de Atendimento à Judicialização da Saúde, que este veio aprimorar as atividades de cumprimento de ordens judiciais, além de garantir maior eficiência, celeridade e desburocratização ao serviço público, tendo, como consequências diretas, mais transparência e eficiência do serviço prestado ao cidadão e menores danos econômicos ao erário, seja pela gestão mais eficiente, seja pela diminuição de penalidades aplicadas ao Estado de Minas Gerais.

Em breve, com sua implementação total e conclusão das fases finais de ajustes, será possível avaliar quantitativamente os benefícios trazidos com a sua criação. 